\title{
Development of the Regional Financial Centers in China: A Quantitative Study Based on the Province-level Data
}

\author{
Zeyun Li \\ Geography Section, School of Humanities, Universiti Sains Malaysia \\ Penang, Malaysia, Email: lizeyun@yahoo.com \\ Sharifah Rohayah Sheikh Dawood \\ Geography Section, School of Humanities, Universiti Sains Malaysia \\ Penang, Malaysia, Email: sdawood@usm.my
}

Doi:10.5901/mjss.2016.v7n3s1p374

\section{Abstract}

\begin{abstract}
In the era of globalization and information proliferation, China is undergoing a remarkable economic restructuring and financial industries' development. This trend of the phenomenon is due to the fact of implications from the financial agglomeration and information spillover, which induced the financial centers' transformation in this vital circumstance. Previous scholars focus more on the western countries' financial centers evolution, and they neglect some deep insights on Asia regions. In the context of this research, we will concentrate on East Asia, particularly China, and to conduct a quantitative analysis of financial centers development based on SPSS application. Since Shanghai is designated as the international financial center and Beijing tends to be admitted as the national financial center in China, however, there are still some insufficient perspectives on the regional financial centers within the China financial centers hierarchies. In this research, we will implement the quantitative methods to evaluate the ability of major provinces in the development of regional financial centers in China. The sample frame is derived from 19 coastal and middle region provinces excluding Beijing, Shanghai and western region provinces. The prime methods of the research are based on the exploratory factor analysis and hierarchical cluster analysis using SPSS, with the combination of some parameters; we can eventually make the general ranking of the corresponding provinces to develop the regional financial centers, as well as carry out the classification of the selected provinces hierarchies. On the whole, the application of the quantitative analysis significantly enhances the precise and holistic evaluation of regional financial centers development in China based on province-level data and that Guangdong, Jiangsu, Shandong and Zhejiang are identified as the next generation of robust candidates for China regional financial centers.
\end{abstract}

Keywords: Regional financial center, Province-level data, Factor analysis, Cluster analysis, China

\section{Introduction}

Financial center as the hub of financial capital, information transmission, plays a dominant role in contemporary economy development and globalization. Reed (1981) is the pioneer to classify the hierarchies of the financial centers using taxonomy, whereby he utilized several parameters to evaluate the financial centers' regional dominance and international embeddedness, thus making the accurate classification of financial centers levels, and the hierarchies are divided into five layers. These layers starts from the highest level to lowest ,which encompass supranational financial centers, first order supranational financial centers, second order supranational financial centers, international financial centers and host international financial centers. Although Shanghai is acknowledged as international financial center while Beijing is assumed as national financial center in China, there is still some shortages of the regional financial centers or subnational financial centers in China. In this article, we will discover the regional financial centers' hierarchies in China, thereby identifying the potential of each province to develop as regional financial centers.

In conjunction to the globalization and world cities' development in Asia, the bulk of financial centers in Asia are experiencing the unprecedented restructuring within this vital context, especially China, Hong Kong and Singapore. Hong Kong and Singapore are the leading financial centers in Asia, in which case they play the benchmarking roles for other Asian countries to draw on. The majority of Asian financial companies' headquarters are eager to access the companies of western counties thereby enhancing their global financial network. The companies located in Hong Kong and Singapore utilized their endogenous competitive advantage and social network, in order to enhance the ties with other associated countries (Meyer, 2015). Through the proliferation of the financial information, knowledge and labor within the 
world economy, the rudiment and paradigm of global financial network are gradually emerging and developing recently. To some extent, a company which is highly embedded in global financial network will be considered more competitive compared to other firms. Likewise, some other scholars also pay much attention to the financial centers' development in Asia. Shanghai and Hong Kong are the two preeminent international financial centers in China, and they have aggressively sought to boost their financial status within the China urban landscape. Shanghai focuses on the small and medium enterprises listing in stock market while Hong Kong exploits the big companies within the array of listing companies. In this context the ultimate objective is to enlarge the complementary mechanism for these two metropolises, whereby they accelerate the transmission of the information and institutional policies to each other (Karreman \& van der Knaap, 2009) . Lai (2012) also emphasized the significance of interdependency among the China financial centers, in which each of the financial centers embed in the financial network of China is characterized by respective functions and roles, such as political, business and offshore finance functions. The division of the functions of the major financial centers in China significantly contributes to financial network formation and complementary relationship. Access to information and multinational company's regional headquarters are two notable centripetal forces to sustain a city to become the financial center. Beijing's irreplaceable locale to attain the regulatory and institutional information consolidate its critical position in China financial center network (Zhao, 2013). The China financial system development still encounters some potential obstacles, especially related to the uneven economy and financial exclusion, and this kind of financial system's uneven development reinforces the foreign banks transfer and centralization in coastal areas in China, where it is the most prosperous region in China (Liu \& Wu, 2008).

Since the location factor plays a dominant role in affecting the multinational companies(MNCs) and foreign direct investment clustering, the majority of financial centers tend to possess an optimal location to attract MNCs and FDI (Dunning, 1998). Zhao, Zhang, and Wang (2004) explain the determinants to form a national financial center in China, whereby they analyze the location selection of MNCs. Compared to other metropolises in China, Beijing maintains a distinctive advantage than other regions to attract MNCs as it has more proximity to central government thereby attaining the non-standardized institutional, political and economic information. In the era of globalization, financial center alliances are warranted though the updating of information technology and government policies (Budd, 1995). Network method is a crucial framework which can demonstrate the global economy and global connections (Dicken, Kelly, Olds, \& Wai-Chung Yeung, 2001). This method has the homogenous impact in the global financial analysis as well. Apart from the independent analysis of global finance or global economy respectively, some scholars also attempt to discover the interrelationship between them. Zhang, Wang, and Wang (2012) demonstrate the positive relationship between financial development and economic transformation within the globalization circumstances and China WTO accession.

In this article we will choose China as the case study in order to exemplify the major financial centers and its hinterland development in contemporary era. A quantitative analysis is conducted for scientific evaluation thereby eliminating the ambiguous results. This kind of valid and credible data can eventually enhance the major financial centers evaluation. Therefore, the major purposes of this paper are to identify the following:

1) To evaluate the salient capabilities of potential provinces in China to develop regional financial centers based upon province-level data.

2) To classify the fundamental clusters of selected provinces embedded in the China financial center hierarchy.

3) To qualify the quantitative methods instrumentally in the financial center research thereby enhancing the deficiency of previous qualitative approaches.

\section{Literature Review}

Kindleberger (1974) is one of the pioneering scholars to identify the financial centres. He demonstrated that finance centre not only coordinates and balances the capital between lenders and borrowers, it also plays a dominant role as medium to balance between different spaces as well.

Thrift (1994) discovered the mutual effect of agglomeration forces and decentralized forces under the global circumstances, information technology innovation and globalization that enhanced the agglomeration forces of financial activities. Daniels (1986) found the intrinsic connections between financial centre development and world city formation. He conducted the quantitative and empirical research in London and New York in terms of foreign bank distributions.

Following the trajectory of financial centers research, geographers began to investigate the urban and regional consequences of international and regional financial centers since twentieth century (Leyshon \& Thrift, 1995). Due to the increasingly financial convergence in most regions and districts, researchers become much more interested in this topic in terms of regional financial development. Leyshon (1995) clarified the concept of Geography of Money and Finance, and emphasized the economic and geographic implications on this subject. Porteous (1995) emphasized the driving 
forces to form and develop the international financial centers, which encompass information hinterland, information attachment, international extremities, path dependence and asymmetric information. These are key determinants to affect a financial center restructuring, whether they are at district, national or international level. Besides, Porteous also found that the number of foreign bank and multinational company is another important factor to evaluate the financial status of a metropolis as these companies are less restricted by the market environment. He implemented the quantitative measurement to distinguish the financial status of different cities, through the method called financial center index (FINDEX).

In an analysis of competition between different financial centers in an economy with different market accessing costs (Gehrig, 2000), Gehrig implemented some scientific methods to analyses several factors which affected the evolution of financial centers, market access costs as a dominant factor, it renders activities to spread over several markets.

After twenty-first century, many Asian scholars began to research Asia international financial centers' development. Zhao $(2004,2005)$ used China as the case study, especially Shanghai, Beijing and Hong Kong, and traced the interrelationship between information flow and financial agglomeration. He applied the MNCs regional headquarters' location choices methods and geographical distributions to further discover the factors to form a national financial center, in which the four criterions for evaluating the location choices are proximity to central policy government, preferential policies, business and investment environment and infrastructure. Based on the research, he found that as Beijing is closer to the central government, it has more advantages to attain the policy information; therefore, it is able to attract more opportunities to become a national financial center in China. He emphasized the informational hinterland and asymmetric information possession as the most significant implications with respect to financial center formations. Lai (2006) concentrated on Shanghai as a case study, and traced the pathway of this city to become an international financial centre. He highlighted the breakthrough during the international financial centre transformation process and also identified the problems and challenges for further improvement. She compared Shanghai with Beijing and Hong Kong to discover its competitive advantages, especially its foreign direct investment (FDI) aspect.

\section{Methodologies}

The analysis of China financial centre tends to utilise the city level data by the previous researchers and scholars. In respect to this research, the province level data is collected so that to enrich the research framework of this area. Admittedly, province level data tends to be more comprehensive and broad than city level data to some extent. In this research, these are fairly considered as the most suitable data sources since it is easy to identify the aggregate economic outputs of financial centre and hinterland of each province irrespective of the location, population and land area. The province level data sources stem from secondary data sources, which encompass the China Statistical Yearbook, Alamance of China's finance and banking, the Peoples' Bank of China and some other financial and institutional departments, as well as a number of web based sources. Hence this kind of collected secondary data is designated for later SPSS analysis.

In this article, quantitative methods are conducted for further discovery. This is due to the fact that most of the previous conspicuous research with reference to financial centres' development tended to concentrate on the qualitative analysis. Obviously, this pattern of the homogenous research is embodied by some underlying deficiencies. In order to remedy the corresponding deficiencies reasonably, a multifarious quantitative method is conducted straightforward using SPSS to qualify the research objectives and boost the diversity and accuracy of this data. SPSS as the leading software in social science data analysis plays a dominant role in the analysis of the collected data. Particularly, the data analysis procedure is composed of three sections, which are exploratory factor analysis, hierarchical cluster analysis and comparative study. In terms of first section, an exploratory factor analysis is underpinned for identifying the determining factors of regional financial centres of major China provinces, and two principle components are demonstrated in this research for later comprehensive marks' analysis and ranking. Subsequently, the SPSS analysis is further transferred into hierarchical cluster analysis in order to make a precise classification of the collected provinces. Obviously, this generalized SPSS analysis enables a more realistic positions' consolidation of China regional financial centres' hierarchies from endogenous and exogenous parameters. Apart from factor analysis and cluster analysis using SPSS, a thorough comparative study and final conclusion about abilities of different provinces where develop regional financial centres are incorporating into this research thereby identifying the intrinsic financial centres' hierarchies between the varieties of provinces. Overall, quantitative analysis is characterised as the most reliable analysis methods towards understanding the China regional financial centre and hinterlands evaluations. 


\section{Analysis and Discussion}

\subsection{Exploratory factor analysis of the regional financial centers' development}

Table 1: Indicator system of financial center development

\begin{tabular}{|c|c|c|}
\hline \multirow{19}{*}{$\begin{array}{l}\text { Financial } \\
\text { center development indicator } \\
\text { system }\end{array}$} & \multirow{3}{*}{$\begin{array}{l}\text { Economic } \\
\text { development indicator }\end{array}$} & Gross regional Product (100 million yuan) \\
\hline & & $\begin{array}{l}\text { Per capital gross regional product(yuan ) } \\
\text { Gross regional product value added by tertiary industry(100 million } \\
\text { yuan) }\end{array}$ \\
\hline & & Average wage of employed person in urban cities (yuan) \\
\hline & \multirow[t]{3}{*}{$\begin{array}{l}\text { Financial } \\
\text { industry development indicator }\end{array}$} & $\begin{array}{l}\text { Number of employed in urban in financial industries ( } 10 \text { thousand } \\
\text { person) }\end{array}$ \\
\hline & & Number of legal entities of financial industries (units) \\
\hline & & Saving deposit of Households(100 million yuan) \\
\hline & \multirow{3}{*}{$\begin{array}{l}\text { Infrastructure } \\
\text { development indicator }\end{array}$} & Length of paved roads (kilometer) \\
\hline & & Length of publication transportation under operation (kilometer) \\
\hline & & Number of postal offices (units) \\
\hline & \multirow{2}{*}{$\begin{array}{l}\text { Information } \\
\text { technology } \\
\text { development indicator }\end{array}$} & Number of internet users (10 thousand person) \\
\hline & & Corporation with e-commerce transactions (units) \\
\hline & \multirow{2}{*}{$\begin{array}{l}\text { Business environment and trade } \\
\text { indicator }\end{array}$} & Total value of import and export (10 thousand US dollars) \\
\hline & & The quantity of registered foreign company (unit) \\
\hline & Education , social culture and service & Enrolment of undergraduate students (people) \\
\hline & \multirow[t]{2}{*}{ indicator } & Number of public libraries (units) \\
\hline & & Number of hospitals (units) \\
\hline & \multirow[t]{3}{*}{ Urban development indicator } & Area of built district ( square kilometers) \\
\hline & & Population density of urban area (people per square kilometers) \\
\hline & & Per capital public green area (square meter) \\
\hline
\end{tabular}

Source: China statistical yearbook, 2015

As a financial center and its hinterland development is not restricted to only one or two determinants or affecting indicators, there are many factors associated to regional financial centers' development. These factors encompass economic, social and cultural aspects. Within this research, we will conduct the indicators system in Table 1 to illustrate the intrinsic driving forces to render the financial agglomeration and regional financial center development. This comprehensive, comparative and scientific indicators system includes economic development indicator, financial industry development indicator, infrastructure development indicator, information technology development indicator, business environment and trade indicator, education, socio-cultural and service indicator, as well as the urban development indicator.

Furthermore, a specifically exploratory factor analysis based on SPSS is applied for further discovery; the data is derived from China statistical yearbook in year 2015 and 19 coastal region and middle region provinces in China were selected for studying and comparing. In general, western region provinces in China are not considered in this study since they are less developed, in terms of urbanization and industrialization for developing as a regional financial center. Besides that, Beijing as the national financial center candidate and Shanghai is assumed to be the international financial center, whereby these two cities are also not examined in this research. Therefore, we conduct the factor analysis for the 19 provinces samples in this research with reference to the major research objectives.

As the exploratory factor analysis will identify the correlation between groups of variables, therefore, we should conduct the correlation test of this research thereby enhancing the accuracy of the research. After enclosing all the data into SPSS, we follow the analysis-dimension reduction-factor analysis procedure, the prospect outputs will be subsequently indicated subject to the corresponding research requirements. The SPSS factor analysis outputs of this research demonstrate that different variables have correlation as shown from correlation matrix. 
Table 2: KMO and Bartlett's Test

\begin{tabular}{|lc|c|}
\hline \multicolumn{2}{|l|}{ Kaiser-Meyer-Olkin Measure of Sampling Adequacy. } & .757 \\
Approx. Chi-Square & 528.510 \\
Bartlett's Test of Sphericity & df & 136 \\
& Sig. & .000 \\
\hline
\end{tabular}

More specifically, The KMO and Bartlett's test from the outputs will examine the factor analysis whether it is suitable to be conducted or not. As we can see from the Table 2, the KMO value (0.757) of the test is more than 0.7 , according to the general standard of $\mathrm{KMO}$ test, if $\mathrm{KMO}$ value is above 0.7 , the factor analysis is accessible to be conducted and it is a moderate value for the majority of factor analysis. Furthermore, in terms of Bartlett's test of sphericity, $p$ value $(0.000)$ is less than 0.001; hence the Bartlett's test is also essentially accepted. Based on the comprehensive analysis of above two values, the variables of the research are suitable for implementing the factor analysis.

Table 3: Total Variance Explained

\begin{tabular}{|c|c|c|c|c|c|c|c|c|c|}
\hline \multirow{2}{*}{ Component } & \multicolumn{3}{|c|}{ Initial Eigenvalues } & \multicolumn{6}{|c|}{ Extraction Sums of Squared Loadings Rotation Sums of Squared Loadings } \\
\hline & Total & $\%$ of Variance & Cumulative \% & Total & $\%$ of Variance & Cumulative \% & Total & $\%$ of Variance & Cumulative \% \\
\hline 1 & 12.264 & 72.142 & 72.142 & 12.264 & 72.142 & 72.142 & 9.761 & 57.420 & 57.420 \\
\hline 2 & 2.278 & 13.400 & 85.541 & 2.278 & 13.400 & 85.541 & 4.781 & 28.121 & 85.541 \\
\hline 3 & .874 & 5.141 & 90.682 & & & & & & \\
\hline 4 & .442 & 2.600 & 93.281 & & & & & & \\
\hline 5 & .331 & 1.947 & 95.229 & & & & & & \\
\hline 6 & .248 & 1.462 & 96.691 & & & & & & \\
\hline 7 & .218 & 1.280 & 97.970 & & & & & & \\
\hline 8 & .131 & .769 & 98.739 & & & & & & \\
\hline 9 & .078 & .459 & 99.198 & & & & & & \\
\hline 10 & .054 & .318 & 99.516 & & & & & & \\
\hline 11 & .031 & .183 & 99.700 & & & & & & \\
\hline 12 & .030 & .178 & 99.877 & & & & & & \\
\hline 13 & .013 & .076 & 99.953 & & & & & & \\
\hline 14 & .004 & .021 & 99.974 & & & & & & \\
\hline 15 & .002 & .014 & 99.988 & & & & & & \\
\hline 16 & .001 & .008 & 99.995 & & & & & & \\
\hline 17 & .001 & .005 & 100.000 & & & & & & \\
\hline
\end{tabular}

Extraction Method: Principal Component Analysis.

The total variance explained of principal component analysis in Table 3 indicate the components general eigenvalue, percentage of variance and cumulative of total variance, we select the eigenvalue values of more than 1 as the principal components, in this research, since the eigenvalues of component 1 and 2 are above 1 and cumulative of total variable is around $85.541 \%$. More precisely, the value of $85.541 \%$ implies that the first two components possess the accumulation of $85.541 \%$ of contribution rate, which means they extremely have the highest potential to explain the majority of information, thus, we justify component 1 and 2 as the principle components.

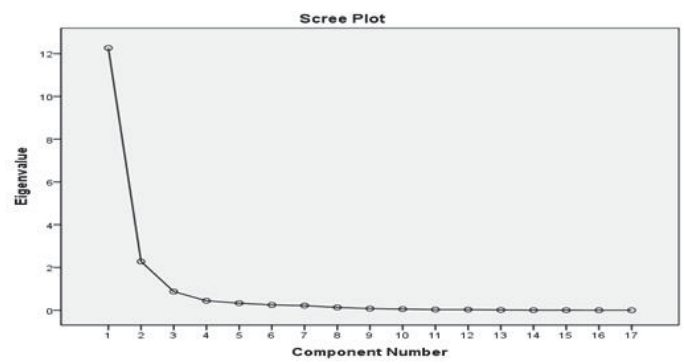

Figure1: Screen plot 
Furthermore, as it can be seen from the scree plot in figure 1, we can also find that component 1 and 2 cover the majority of information, they are situated at the steepest location of the graph while the remaining values are maintaining at the flat position of the scree plot graph.

Table 4: Rotated Component Matrix

\begin{tabular}{|l|c|c|}
\hline & Component \\
\cline { 2 - 3 } & 1 & 2 \\
\hline Zscore: Gross regional product (100 million yuan) & .839 & .510 \\
Zscore: Gross regional product value added by tertiary industry(100 million yuan) & .893 & .421 \\
Zscore: Average wage of employed person in urban cities & .719 & .552 \\
Zscore: Number of employed in urban in financial industries & .745 & .602 \\
Zscore: Number of legal entities of financial industries & .857 & .402 \\
Zscore: Saving deposit of Households & .820 & .548 \\
Zscore: Length of publication transportation under operation & .909 & .342 \\
Zscore: Number of postal offices & .824 & .461 \\
Zscore: Number of internet users & .751 & .614 \\
Zscore: Corporation with e-commerce transactions & .912 & .150 \\
Zscore: Total value of import and export & .930 & .155 \\
Zscore: The quantity of registered foreign company & .959 & .081 \\
Zscore: Enrolment of undergraduate students & .435 & .734 \\
Zscore: Number of public libraries & .038 & .950 \\
Zscore: Number of hospitals & .370 & .818 \\
Zscore: Area of land used for urban construction & .790 & .551 \\
Zscore: Per capital public green area & .381 & .197 \\
\hline
\end{tabular}

Extraction Method: Principal Component Analysis.

Rotation Method: Varimax with Kaiser Normalization.

a. Rotation converged in 3 iterations.

Since the original component matrix cannot fundamentally identify the major factor loadings, the conduct of rotated method is remarkably coped with this issue simultaneously.

According to Table 4, after we conduct rotated component matrix same to original component matrix in order to eliminate the unclear factors, we can find that component 1 is more associated with the economic development, financial industry development, as well as the business environment and trading indicators while component 2 has significant factor loading upon the infrastructure and public services parameters. Therefore, we define the principle component 1 as the economic and finance factor and component 2 as the infrastructure and public service factors. Generally, the links of the two principle components are warranted for subsequent factor scores and comprehensive scores analysis.

Table 5: Ranking of provinces in terms of factor score and comprehensive score

\begin{tabular}{lcccc}
\hline City & FAC1_1 & FAC2_1 & Comprehensive Score & Ranking \\
\hline Guangdong & 2.57041 & .66161 & 1.94 & 1 \\
Jiangsu & 1.95526 & .13892 & 1.36 & 2 \\
Shandong & .77588 & 1.49318 & 1.01 & 3 \\
Zhejiang & 1.44382 & -.62726 & .76 & 4 \\
Hebei & -.56094 & 1.32144 & .06 & 5 \\
Henan & -.68094 & 1.51283 & .04 & 6 \\
Liaoning & -.21944 & .35702 & -.03 & 7 \\
Hubei & -.27621 & .22424 & -.11 & 8 \\
Fujian & .10483 & -.74524 & -.17 & 9 \\
Anhui & -.33298 & .05639 & -.20 & 10 \\
Hunan & -.61623 & .56686 & -.23 & 11 \\
Jiangxi & -.70948 & .22586 & -.40 & 12 \\
Tianjin & .51698 & -2.40405 & -.44 & 13 \\
Shanxi & -.79182 & .23589 & -.45 & 14 \\
Heilongjiang & -.77740 & .16194 & -.47 & 15 \\
Inner Mongolia & -.46409 & -.53400 & -.49 & 16 \\
\hline
\end{tabular}




\begin{tabular}{lllll}
\hline Guangxi & -.72074 & -.21134 & -.55 & 17 \\
Jinan & -.63777 & -.65925 & -.64 & 18 \\
Hainan & -.57913 & -1.77501 & -.97 & 19 \\
\hline
\end{tabular}

According to Table 5 above, the factor score is acquired after the rotation analysis and saving finished, we utilized the formula based on the factor score and corresponding contribution rate to attain the comprehensive score of 19 cities. The table clearly illustrates that Guangdong, Jiangsu, Shandong and Zhejiang are the four provinces that have the highest comprehensive score and ranking no.1 to 4 of the urban hierarchies. In other words, these four provinces are relatively speculated to have the highest potential to develop as the regional financial centers. As compared to the previous four provinces, the remaining 15 provinces are detected with lower comprehensive score and less competitive to construct the regional financial centers.

\subsection{Hierarchical cluster analysis of regional financial centers' development}

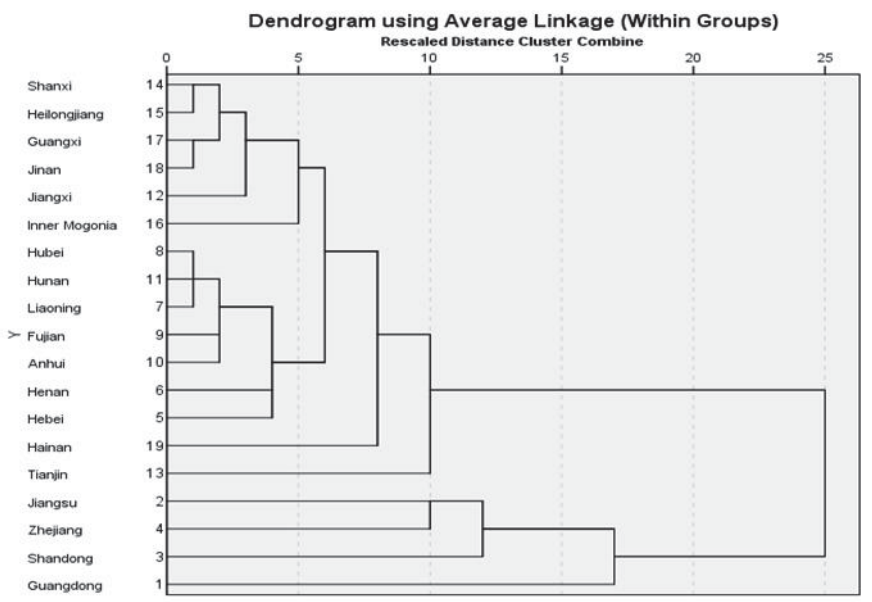

Figure 2: Dendrogram using average linkage (Within groups)

Through the holistic exploratory factor analysis of major parameters, we can conventionally identify the two principle components that have the endogenous effects on the regional financial centers and hinterlands development. In order to generate the classification of China province level samples and clarify the neglected theorization and questions in factor analysis, cluster analysis should be taken into account for the more scientific and reliable results. Essentially, we utilized the original parameters in the factor analysis accordingly for the provinces classifications in order to enhance the explicit analysis results.

Eventually, the results can be easily identifying the effect of parameters on the regional financial centers and hinterlands development. As we can see from Figure 2, the major provinces in this sample are roughly divided into three clusters; the first cluster encompasses Guangdong, which is the superior province in China with the highest economic output and international trade. Guangdong province has two preeminent potential cities to construct the regional financial centers, which are Guangzhou and Shenzhen, as well as huge territories of financial and economic hinterlands surrounding them. Guangdong is generally considered the leading provinces to formulate the regional financial centers strategy in China. While the second cluster is composed of Jiangsu, Shandong and Zhejiang, these three provinces also have the highest comprehensive score in the factor analysis; they are characterized as the second level provinces to build the regional financial centers following Guangzhou in China. Then, the remaining provinces in cluster analysis are incorporated into third cluster. They tend to be considered as the less competitive provinces to evolve the regional financial centers as compared to the first two clusters due to the less economic financial agglomeration, and narrow information hinterlands. 


\section{Concluding Remarks}

This research paper comprehensively and explicitly evaluate the ability of the potential China provinces to develop the regional financial centers and hinterlands trajectory. Since Shanghai is designated as the China international financial center while Beijing is recognized as the China national financial center, admittedly, within China urban hierarchies, there is still a shortage of regional financial centers embedded in third level of China financial networks. Thus, a logistic quantitative method is conducted to assess each province underlying dynamics to build potential regional financial centers and hinterlands in China. Therefore, this can determine the regional financial center of each region in order to pursue development in China nation-state territory. In order to exemplify the more precise regional financial centers and hinterlands analysis, we carry out the province level data analysis rather than city level data thereby identifying more broad coverage of the financial centers and its hinterlands. Specifically, the factor analysis using SPSS of province data concretely identify two major principle components and evaluate the corresponding comprehensive score. Consequently, we can find that Guangdong, Jiangsu, Shandong and Zhejiang provinces have the highest potential to develop as the regional financial centers as the result of highest comprehensive scores indicators and fundamental rankings. In addition to the factor analysis through SPSS, we utilized the original parameters from the factor analysis to conduct the cluster analysis in order to making the remarkable classification of selected provinces. The application of hierarchical cluster analysis based on the group method is specifically divided with the selected provinces into three clusters. The first cluster is Guangdong, the second tier comprising Jiangsu, Shandong and Zhejiang, while the remaining provinces are targeted into third spectrum. As making comparison between two methods through SPSS, we can illustrate that Guangdong, Jiangsu, Shandong and Zhejiang are the provinces that have the highest potential to develop the regional financial centers since they possess the highest comprehensive score based on factor analysis while they also locate in the first and second tiers of ranking of cluster analysis classification. Besides, since the factor analysis and cluster analysis have the consistent results, we can conclude that China government should give the priority to these four provinces to construct the regional financial centers, thereby enhancing the global competition of China and to make it embedded in the international financial networks.

\section{Acknowledgements}

The authors would like to thank Universiti Sains Malaysia for supporting this research through the USM Fellowship.

\section{References}

Budd, L. (1995). Globalisation, Territory and Strategic Alliances inDifferent Financial Centres. Urban Studies, 32(2), 345-360. doi:10.1080/00420989550013121

Daniels, P. W. (1986). Foregign banks and metroplitan development: a comparision of London and New York. Tijdschrift Voor Economische En Sociale Geografie, 77(4), 269-287. doi:10.1111/j.1467-9663.1986.tb00134.x

Dicken, P., Kelly, P. F., Olds, K., \& Wai-Chung Yeung, H. (2001). Chains and networks, territories and scales: towards a relational framework for analysing the global economy. Global Networks, 1(2), 89-112. doi:10.1111/1471-0374.00007

Dunning, J. H. (1998). Location and the multinational enterprise: A neglected factor? Journal of International Business Studies, 29(1), 45-66. doi:10.1057/palgrave.jibs.8490024

Friedmann, J. (1986). The World City Hypothesis. Development and Change, 17(1), 69-83. doi:10.1111/j.1467-7660.1986.tb00231.x

Gehrig, T. (2000). Cities and the Geography of Financial Centers. In J.-M. H. a. J.-F. Thisse (Ed.), Economics of Cities: Theoretical Perspectives. Cambridge: Cambridge University Press.

Hall, P. M. (1966). The world cities. London: Weidenfeld \& Nicolson Publishing.

Karreman, B., \& van der Knaap, B. (2009). The financial centres of Shanghai and Hong Kong: competition or complementarity? Environment and Planning A, 41(3), 563-580. doi:10.1068/a40230

Kindleberger, C. P. (1974). The Formation of Financial Centres: A Study of Comparative Economic History. Princeton: Princeton University Press.

Knox, P. L., \& Peter J. Taylor, e. (1995). World Cities in a World System Cambridge: Cambridge University Press.

Krugman, P. (1991). Increasing Returns and Economic Geography. Journal of Political Economy, 99(3), 483-499. doi:doi:10.1086/ 261763

Lai, K. (2006). Developing Shanghai as an International Financial Centre: Progress and Prospects. China Policy Institute \& Centre for Global Finance, Working Paper, 200602.

Lai, K. (2012). Differentiated Markets: Shanghai, Beijing and Hong Kong in China's Financial Centre Network. Urban Studies, 49(6), 1275-1296. doi:10.1177/0042098011408143

Leyshon, A. (1995). Geographies of money and finance I. Progress in Human Geography, 19(4), 531-543. doi:10.1177/03091325 
9501900406

Leyshon, A., \& Thrift, N. (1995). Geographies of Financial Exclusion: Financial Abandonment in Britain and the United States. Transactions of the Institute of British Geographers, 20(3), 312-341. doi:10.2307/622654

Liu, W. D., \& Wu, W. (2008). Development of local financial systems in mainland China. Eurasian Geography and Economics, 49(2), 160-179. doi:10.2747/1539-7216.49.2.160

Meyer, D. R. (2015). The world cities of Hong Kong and Singapore: Network hubs of global finance. International Journal of Comparative Sociology, 56(3-4), 198-231. doi:10.1177/0020715215608230

Nigel Thrift , S. C., Ron Martin (1994). Money, Power and Space: Wiley-Blackwell.

Porteous, D. J. (1995). The geography of finance: Spatial dimensions of intermediary behaviour. London: Avebury.

Reed, H. C. (1981). The Preeminence of International Financial Centers. New York: Praeger.

Sassen, S. (1991). The Global City: Princeton University Press.

Zhang, J., Wang, L. F., \& Wang, S. S. (2012). Financial development and economic growth: Recent evidence from China. Journal of Comparative Economics, 40(3), 393-412. doi:10.1016/j.jce.2012.01.001

Zhao, S. X. B. (2013). Information Exchange, Headquarters Economy and Financial Centers Development: Shanghai, Beijing and Hong Kong. Journal of Contemporary China, 22(84), 1006-1027. doi:10.1080/10670564.2013.795313

Zhao, S. X. B., Cai, J. M., \& Zhang, L. (2005). Asymmetric information as a key determinant for locational choice of MNC headquarters and the development of financial centers: A case for China. China Economic Review, 16(3), 308-331. doi:10.1016/j.chieco.2005. 02.006

Zhao, S. X. B., Zhang, L., \& Wang, D. T. (2004). Determining factors of the development of a national financial center: the case of China. Geoforum, 35(5), 577-592. doi:10.1016/j.geoforum.2004.01.004 